\title{
Development and Application of Interactive Virtual Tour to Berdyansk State Pedagogical University
}

\author{
Anna Alekseeva ${ }^{1}$,Jose Italo Cortez ${ }^{2}$, Vitaliy Mezhuyev ${ }^{3}$, \\ Gregorio Trinidad Garcia ${ }^{2}$, Liliana Cortez ${ }^{2}$,Jose Miguel Hurtado Madrid ${ }^{2}$, \\ Carlos A. Rios Acevedo ${ }^{2}$, Monserrat Huerta Chiquillo ${ }^{2}$ \\ ${ }^{1}$ Department of Informatics and Software Engineering at Berdyansk State Pedagogical University, Ukraine \\ ${ }^{2}$ Research Laboratory in Digital Systems and Renewable Energy, Faculty of Computer Science, Benemerita \\ Autonomous University of Puebla, Mexico \\ ${ }^{3}$ Faculty of Computer Systems and Software Engineering, University Malaysia Pahang
}

\begin{abstract}
Introduction of modern computer technologies, namely the development of interactive virtual objects in the learning process can achieve significant results in terms of dynamic update of the educational process organization, its forms and methods; it will also give students an opportunity to actively participate in the preparation and implementation of these changes.Development of an interactive model of architectural tour to Berdyansk State Pedagogical University with the help of three-dimensional graphics is actual because, firstly, in the present time there is no visualization of this architectural complex from the aesthetic and historical perspective. The University building has an interesting history, and we as the heirs need to preserve the memory of it. Secondly, there's a cognitive and informative component: you can always help an applicant, a student, a lecturer or a visitor to plunge into the atmosphere of the educational establishment, see the plan of the lecture rooms, and show to a general viewer the architectural elements and to interact with many elements of the interior space. Thirdly, this project can be used in advertising and career-oriented work. And it is an affordable and easy resource due to intensive development of computer technologies, one of the important directions of which is Internet-based technologies.
\end{abstract}

Keywords: Interactive model, computer technologies, three-dimensional graphics.

\section{INTRODUCTION}

Computer technologies provide access to handling of a practically unlimited amount of information that provides direct involvement in the information flow of society. They are universal means of cognitive research, the second largest after the traditional symbolic writing instrument that provides rapid exchange of information about the content of carried out activities [1].

In the modern society, the construction of three-dimensional images (3D) due to its qualitative characteristics is the most rapid developmental trend in computer technologies, including computer graphics[2,3].

Three-dimensional graphics are actively used to create images in the square of a screen or a sheet of printed materials in science and industry, such as automation systems design work (CAD, to create solid-state elements: buildings, machinery parts, machinery) architectural visualization (this applies to so-called "virtual Archaeology") in modern medical visualization systems $[4,5,6,7]$. It is the most widely used in modern computer games, and is also anelement of cinema, television, print production, etc.
A wide range of information and computer technologies offers the ability to create virtual objects, thus allowing you to expand the practical training of students, providing a truly new level of presentation of educational material, allow you to make learning more effective and intense[8].

The use of $3 \mathrm{D}$ editors in the training of future engineers-teachers is an effective means of organizing of practical mastery and use of ICT in various forms of life of an individual.

In the context of our project the development of an interactive architectural tour to Berdyansk State Pedagogical University by means of three-dimensional graphics will contribute to a deeper and informative study of subjects connected with computer graphics, whose main purpose is: to familiarize students with the current state and prospects of development of computer graphics, learning of basic techniques of computer graphics of packages in order to create illustrated products; acquisition of skills and abilities by students of using raster and vector graphics, computer graphics packages to address common challenges in their future careers[4]. 


\section{DEVELOPMENT OF THREE- DIMENSIONAL GRAPHICS AS A COMPONENT OF COMPUTER GRAPHICS FOR THE DEVELOPMENT OF AN INTERACTIVE MODEL}

Nowadays, thanks to the grand development of computer technologies, some aspects of our life are unimaginable without the use of computer technologies, including those which are without computer graphics. These are, above all: modeling, project and design development; all kinds of printing processes; almost all the advertising industries; television and so on.

In recent years based on computer graphics and other advanced technologies the completely new, not like anything previously known areas of production, profession, relationships and even the environment appeared. For most of us the concept of "virtual reality", "Internet Zone", "teleconference", "live audio and video", etc. are a familiar sound.

The consequence of the invasion of computers in almost all areas of human activity is an emergence of new types of art. These can include music and computer animation [9]. The latter appeared just because of one of the types of computer graphics, namely three-dimensional graphics and animation.

Three-dimensional graphics is part of computer graphics, the set of methods and tools (both software and hardware), dedicated for threedimensional image of objects.

A three-dimensional image on a square is different from a two dimensional one in such a way that it involves the construction of geometric projection of three-dimensional model of the scene onto the square (e.g. computer screen) with the help of specialized programs (however, with the creation and implementation of 3D- displays and 3D- printers, three-dimensional graphics not necessarily involve projecting on the square) [10]. With it this model can correspond both to the objects of the real world (cars, buildings, a storm, an asteroid) and be fully abstract (the projection of the four-dimensional fractal)[11].

This type of graphics, or rather, class of $3 \mathrm{D}$ editors became rather widespread in the last 1-2 years not only in the experts' circles, which use very strong specialized graphic stations, but in the circles of users of the middle qualification. This, above all, is due to the development aimed at work with 3D graphics not only of software, but also the emergence of hardware, aimed as well at support and acceleration of various $3 \mathrm{D}$ processes. These tools include the following:
- 3D accelerators, which are part of almost all modern video cards;

- $\quad$ processors with support of MMX command;

- $\quad$ specialized processors such as RISC, Silicon Graphics;

- processors with support of new 3D NOW technology et al.

Three-dimensional graphics usually deal with a virtual, imaginary three-dimensional space that appears on a square, two-dimensional surface of a screen or a paper. The main difference of 3D from the two-dimensional graphics is that $3 \mathrm{D}$ image is characterized not only by length and width, but also by such parameters as depth.

Depending on the principles of imaging, there are several kinds of 3D graphics: polygon, analytic, fractal and spiel. The most common variety of $3 \mathrm{D}$ graphics is a polygon graph, the main principle of which lies in the choice of a minimal surface (polygon), whose role is usually played by a triangle. You can create any object as a structure or a massif. This type of computer graphics has absorbed a lot of the vector, as well as of theraster computer graphics. It is used in the development of interior design projects, architectural sites, in advertising, in the creation of educational computer programs, video clips, vivid images and details of products and so on. Three-dimensional computer graphics allow you to create three-dimensional modeling of three-dimensional scenes with lighting conditions and installation viewpoints[12,13].

To study ways and means of composition, such as the transmission of space, environment, light and shade, the laws of linear and aerial perspectives of color, benefits of this type of computer graphics over vector and raster graphics are obvious. In three-dimensional graphics images (or characters) are modeled and moved in the virtual space, in the environment or in the interior, and their animation allows seeing the object from any point of view, moving to artificially created environment and space, of course, accompanied by special effects.

Three-dimensional computer graphics as vector ones are object-oriented, which allow you to change both all the elements of three-dimensional scenes and of each object separately. This type of computer graphics has great potential to support technical drawing. Using three-dimensional graphical editors of computer graphics, such as Autodesk 3D Studio, you can perform a visual representation of parts, and perform a layout of buildings and architectural sites.

To provide a more realistic view threedimensional computer graphics allow modeling of objects with transmission of textures and structures of materials. Ability to see the layout of the product 
from any points of view before its realization in the material allows making changes and corrections to its form or proportion that can be no longer possible after the start of work. In the same direction, three-dimensional computer graphics can be used to support the sculpture, design, and art graphics. Volumetric three-dimensional animation and special effects are also created by means of three-dimensional graphics. The major application of these features of three-dimensional computer graphics can be making educational movies for tutorials[14,15].

Thus, 3D modeling is a process of creating a three-dimensional model of an object. The task of 3D modeling is to develop a visual volumetric image of a desired object. Using three-dimensional graphics one can create an exact copy of a subject, and to develop a new, even unrealistic idea that until this point the object didn't exist.Let's consider the stages of development of an interactive model of architectural tours to Berdyansk State Pedagogical University with the help of threedimensional graphics.

\section{ANALYSIS OF COMPUTER PROGRAMS FOR DEVELOPING OF AN INTERACTIVE THREE- DIMENSIONAL MODEL}

There are very many programs for threedimensional modeling, visualization and animation. We perform an analysis of software for 3D modeling. Art of Illusion is a software for 3D modeling, texturing, ray tracing and rendering of static images or animation, which is a powerful tool for 3D modeling. Despite the simple interface, there are many features that can be found in expensive software packages.

DeleD 3D Editor is a free program designed to create content for your game project. With this application, you can create static objects of the world. The program combines the functional needs to create complex 3D- scenes with intuitive interface: to build the whole world during an hour! Concepts DeleD are simple. It's possible to drag and manipulate with 3D objects like cubes, broken lines, spheres, rectangles, grids, pyramids, cylinders etc. The program can also be used in other areas such as training, web design, prototypes and images creating.

Sketch Up is a program for modeling of relatively simple three-dimensional objects buildings, furniture, and interior. In March 2006, it was acquired by Google. In April 2012, Google sold Sketch Up to the company Trimble Navigation for $\$ 90$ million. There are two versions - a free with limited functionality (especially about export to other formats) and paid (Sketch Up Pro, \$ 590). Now, instead of Sketch Up to create 3D- models of buildings in maps, Google offers an online tool "Architect".

TrueSpace is a program for work with three-dimensional objects. With it you can create high-quality 3D-animation with realistic lighting, textures, etc. The resulting three-dimensional models can be used in games; they can also be imported into the virtual worlds such as Virtual Earth.

Now3D is a free program, easy to use. It includes an editor, a program for rendering and a browser. In Now3D all major features of creating 3D- images are implemented. The workspace of the program is divided into six windows that give you an opportunity to watch the object from any side. The camera placement can be easily changed. You can do this by using a mouse as well as setting the coordinates in a special way. There are a modeling apparatus and a system of ray tracing. After creating a three-dimensional image, it's necessary to conduct a rendering. For this purpose, there is a built-in utility under the name Now3D Renderer. The view of the final image is made by a built- in Now3D review.

$\mathrm{K}-3 \mathrm{D}$ is a software system, system of 3Dmodeling and computer animation. It is a fullfeatured and powerful editor for creating animated $3 \mathrm{D}$ models. The program includes many templates and models, and may expand its modeling capabilities by installing plugins.

We have chosen 3D Studio MAX - the market leader of software for three-dimensional modeling, Figure 1, animation and visualization[16,17].

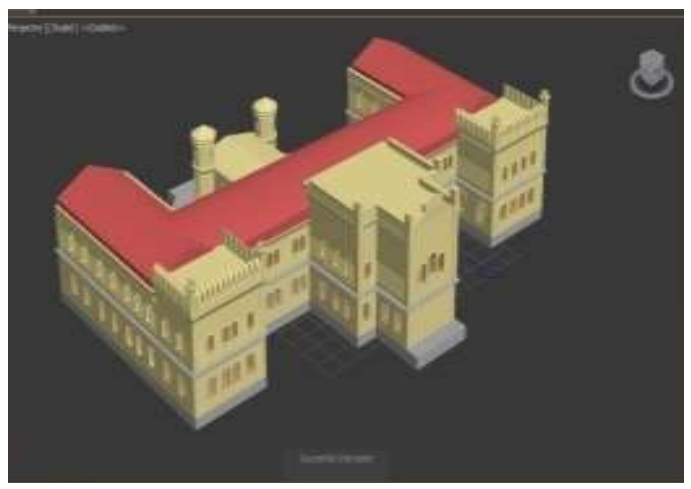

Figure 1. Building of block 1, details of the decoration elements.

This is one of the most famous threedimensional editors and it has huge tools to create different shapes and complexity of threedimensional computer models of real or fantastic objects of the surrounding world using a variety of techniques and devices, which include the following: Polygonal modeling which includes the Editable mesh (editable surface) and the Editable 
poly (editable polygon) - the most common modeling method WHICH is used to create complex models; modeling based on non-uniform rational B-splines (NURBS); modeling based on Bezier surface portions (Editable patch) is suitable for modeling of bodies rotation; modeling with the use of built-in libraries of the standard parametric objects (primitives) and modifiers.

Blender was chosen as the engine of an interactive model - a Cross-platform graphics 3D package with an open source code. Despite its relatively small size, this pack has such functions which are enough for work both of a normal user, and of experts. Blender includes: tools of 3D modeling, animation, rendering, visualization, video processing, set of options for creating of interactivity, visual 3D-effects, etc. Using this program, you can create 3D- pictures close to reality, with the quality of a digital photo.

We also used the program Autodesk Mudbox - a professional graphics program designed for modeling of high poly digital sculptures and texture painting of 3D models. In the Figure 2 It gives an opportunity for professionals in modeling and artists in textures to create digital 3D objects and 2D sketches, as if they work with clay and paints.

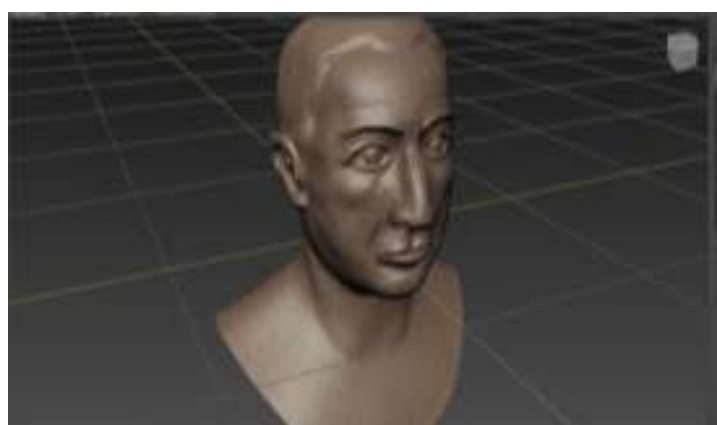

Figure 2. The trial modeling of V. Khavkin bust

Thus, to develop an interactive threedimensional model of Berdyansk State Pedagogical University, we used the last three programs. They allow creating quite complex models in their structure, texturing them and doing the animation.

\section{DEVELOPMENT OF AN \\ INTERACTIVE MODEL OF \\ ARCHITECTURAL TOURS TO BERDYANSK STATE \\ PEDAGOGICAL UNIVERSITY WITH THE HELP OF THREE- DIMENSIONAL GRAPHICS}

Let us consider in more details the stages of an interactive model creating of an architectural excursion.

Stages of development:
1. Organizational;

a. Statement of tasks, objectives of the project

b. Negotiations with the administration on providing the necessary information

c. Organization of the process

2. Development;

a. Collection of materials (Preproduction)

i. Photo;

ii. Text;

iii. Drawings

b. The main development of the model (Production);

i. Development of the model;

ii. Integration with the game engine;

3. Presentation;

\section{Organizational stage}

First of all, the aims and objectives of the project were set to meet the following conditions:

1. The university building is a historical monument of the 17th century and its visualization is an aesthetic and historical contribution to Ukraine;

2. The development has a cognitive and informative component, it is always possible to help an applicant, a student, a teacher or a guest to orientate in an educational institution, familiarize with the lecture rooms' plan, show architectural elements to an ordinary viewer and interactively communicate with many elements of the premises' interior;

3. The project can be used in advertising and career-oriented work.In the further course of the work we needed to obtain permission from the administration of the university to develop an excursion: to photograph the premises, the interior of the first university's building; to get plans of floors and premises of the building.The organization of the development process was carried out in the following way: information collecting about the object of modeling (the first building of BSPU) then working separately with creating the model and integrating it into the game engine (first in Blender and later in Unity).

\section{Development}

The development began with the collection of materials: the camera took photos of the main and most interesting places of the first building of BSPU. Especially it's worth mentioning the assembly hall and the entrance hall, which can be of the audience's special interest.The development of the model of the first building was carried out in the following way.First, based on the collected information (photos, drawings), a basic model was built in the Autodesk 3ds max application, after which empty spaces and halls were filled with various furniture and other objects, then images of real walls were projected onto the walls of the 
room, thereby simulating optical Properties of real world objects. At the end of the model development, some preparatory manipulations were made for export into the game engine[17].

Integration into the game engineafter importing models and images (textures) into the game engine, writing scripts began that would have allowed the user to navigate through the model (moving, rotating the camera, jumping, etc.)The final part of the integration was lighting set in the premises, which was carried out in accordance with their actual location.

\section{Presentation}

The presentation of the interactive model of the architectural excursion around Berdyansk State Pedagogical University was the last stage, after which it was placed on the main page of the website of Berdyansk State Pedagogical University http://bdpu.org/3d.html and was approved during 3 years.Methodical recommendations for the installation and operation of the program have been developed.The development of our project was in a detailed modeling of the university building, its exterior (some adjacent buildings) and the interior, visualization and animation, virtual tour. The source of information to create a model was the photo, the university plans and the observations.

The ability to model a variety of shapes and constructions using various software tools and knowledge of orthogonal (rectangular) and the central projection is one of the directions of training of future engineers-teachers of computer profile.Creating of the objects with the help of three-dimensional graphics involves several stages. The first step is to create a form of a subject or an object. This program creates it in a geometric form - from a variety of flat shapes, mostly triangles Figure 3 and Figure 4.

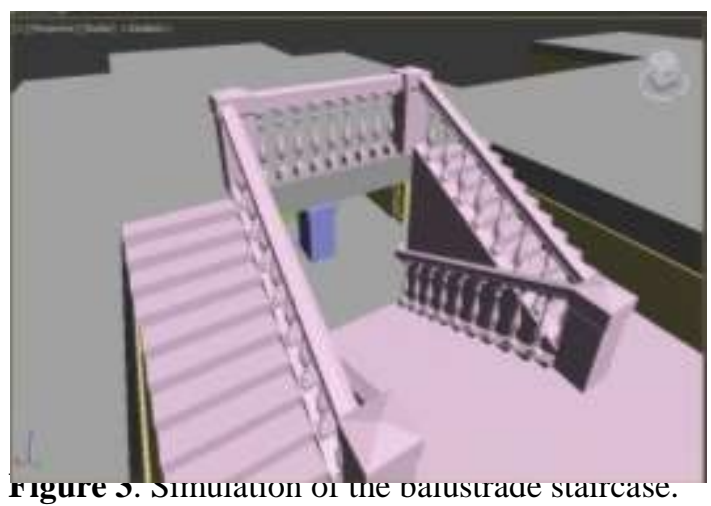

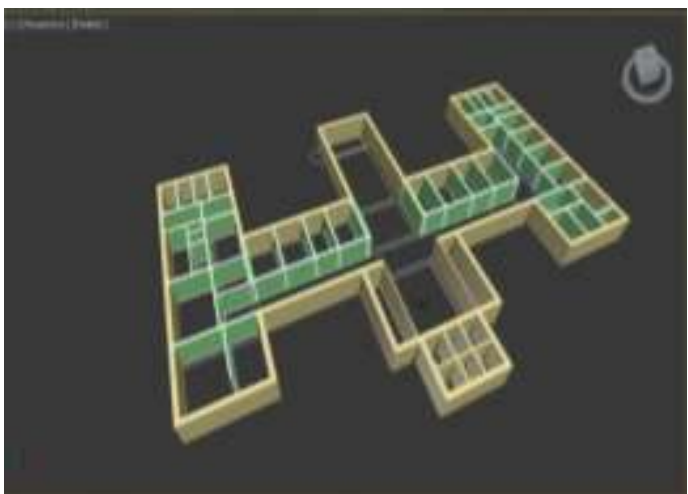

Figure 4. Building of the walls after the layout, taken from the University schemes.

Then we detailed the model, when the "skeleton" of the building gives the "revival" to the model, Figure 5.

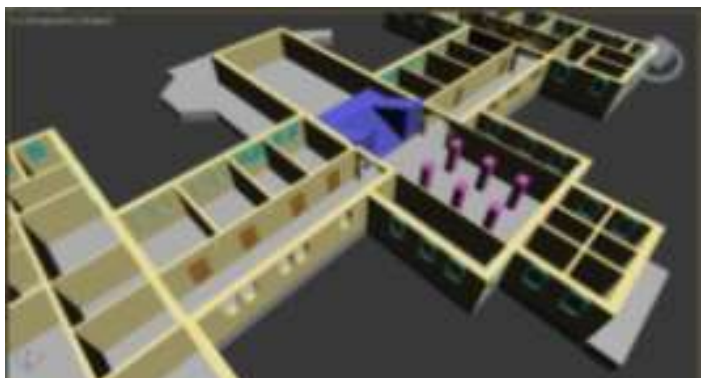

Figure 5. Detailing of the basic elements of the building (windows, doors, stairs, etc.).

Then all the corners are smoothed, the geometric model becomes smooth and the forms have roundness of lines, Figure6.

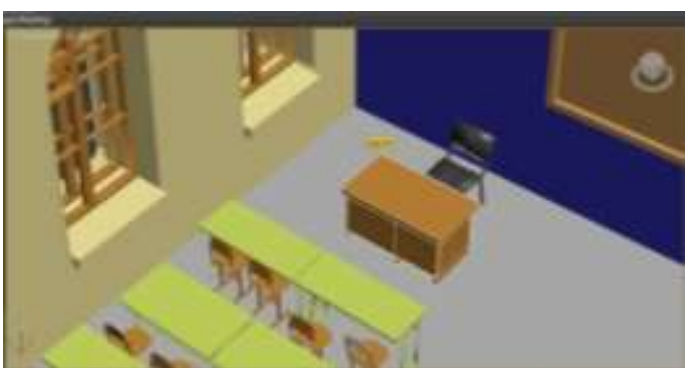

Figure 6. Work on the interior of the reading rooms

The next step - the figure is given the texture and the color Figure 7, several options for lighting are given and the whole scene is visualized. Thus, we get a very real figure, subject, or an object that can be considered not only from one side of the square (in two dimensions), but from all sides, including its depth. 


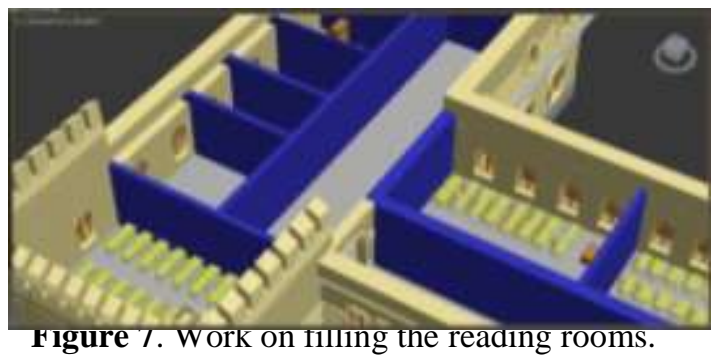

The wall's color is different from the color of the facade because they are different objects. Their separation was necessary for an easy editing of the model (the facade is rather complex and multi-polygonal and its development without necessity just slows our working process).With Autodesk Mudbox we modeled high poly digital sculptures and texture painting of 3D models. Then followed the work with the game engine Blender Game Engine, which was in importing the previously developed models of the University and in implementation of the function of moving in this model. Game engine acts as an interface between the user and the design of the model and enables him to interact with it, Figure 8.

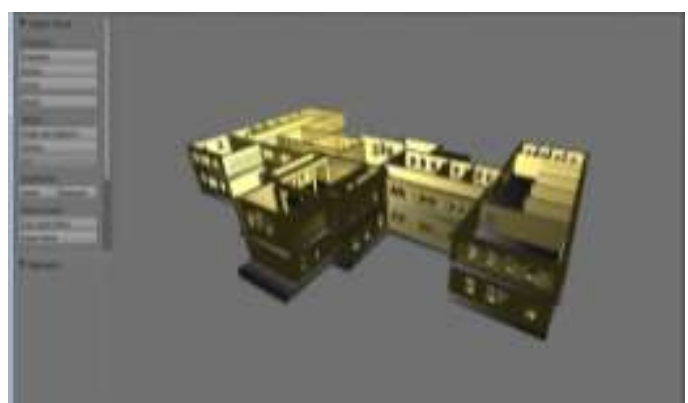

Figure 8. Theimportedmodel of the universityto the engine Blender.

The main tool when working with Blender is the Game Logic, in which all the basic physical and logical functions are set. Almost all the major parameters are set in the Scene tab of the Properties menu. In the same menu, there are tabs with the configuration of physics of the world, the general parameters of the selected object, texture, physical properties, etc.

The Logic Editor tool, in which the interaction between the objects of the engine is directly determined, connects sensors (Actuator, Always, Collision, Delay, Joystick, Keyboard, Message, Mouse, Near, Property, Radar, Random, Ray), logics (and, or, Nand, Nor, Xor, Xnor) and actions (Action, Camera, Constraint, Edit Object, Filter 2D, Game, Message, Motion, Parent, Property, Random, Scene, Steering, Sound, State, Visibility).

Instead of logical functions, you can choose a sided script in the programming language
Python (for example, while adding the work with the camera using the mouse), Figure 9.

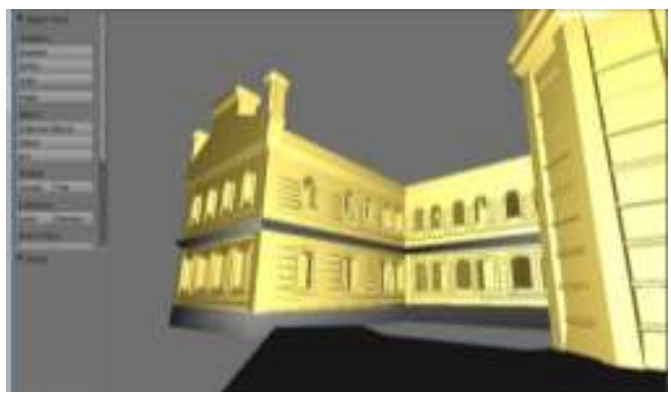

Figure 9. View of the model of the university from the first person.

Any actions can be set to the objects, such as opening a door or swinging a camera. These actions are recorded using a separate tool or groups of instruments: Dope Sheet, Time Line and the menu of Properties. In the Dope Sheet the time duration for the animation of these object properties is shown. In the Time Line the total time scale is displayed, and in Properties the properties of objects in a pre-selected time are set. Despite the overall scale of time each animation is independent and works independently [18].During the development, some problems were added: the wrong strategy of the interiors modeling had been chosen.The problem is that the modeling of interiors and adding them to the finished model is difficult both for the computer and for $3 \mathrm{ds}$ Max. If the model is growing very rapidly, the auto-save of the data is taking much time. There are also problems with importing (exporting of the whole interior is immediately possible, but its importing into Blender is impossible because the file takes drastically much space).The solution: to use a new strategy - all the interior elements are modeled in a single sample and later are placed in Blender as required.

Very good quality of modeling is achieved through a careful selection of textures and materials combined with the correct placement of light sources in the scene and in cameras. The basis for the construction of a spatial form is a square and a facet of an object. The plane in a three-dimensional graph is given with the help of three points connected by straight line segments. It is this condition that makes it possible to describe using the derived surfaces "spatial grid", which is a model of the object. Then the object is additionally assigned the surface characteristics of the object the material. In its turn, the material characterizes the quality of surfaces such as polished, rough, shiny, etc. Its texture (stone, fabric, glass) is also described. The optical properties such as transparency, reflection and refraction of light rays, etc. are given, too[19]. 
At the same time, three-dimensional objects can be given the lighting conditions and the view (camera) can be selected to obtain the most interesting visual image. The setting that consists of a three-dimensional object, the lighting conditions and the chosen perspective is called "a threedimensional scene". But to describe the threedimensional space and the object that is inside it, the coordinate method is used. This is a visualization of the process of a user's interaction with the model in the finished product from the first person.Thus, three-dimensional graphics is a big science in which it's possible to improve knowledge and skills throughout the whole life, and that is a component in the training of future engineers and educators to use it.

\section{CONCLUSIONS AND PROSPECTS FOR THE FUTURE RESEARCH.}

The development of computer science, information and communication technologies necessitates the expansion of advanced training, using of the latest technical and software tools, improving of teaching methods, development of nonlinear and adaptive learning technologies.We have developed an architectural tour to Berdyansk State Pedagogical University by means of the use of $3 \mathrm{D}$ editors in the process of training of future engineers-teachers of the computer type. Thanks to the fact that 3D graphics have a certain degree of information content and allows to introduce more fully the external characteristics of an object, photo-realistic images of architectural forms of the university were created. Using 3ds Max with the game engine of Blender Game Engine for architectural visualization in conjunction with other Autodesk applications with flexible settings [20], a professional graphics program Autodesk Mudbox for modeling high poly digital sculptures and texture painting of 3D models, we have created an interactive virtual model of the university.

The main contributions to the creation of an interactive model of an architectural excursion around Berdyansk State Pedagogical University using three-dimensional graphics are:

1. The university building is a historical monument of the 17th century and its visualization is an aesthetic and historical contribution for Ukraine;

2. The development has a cognitive and informative component, it is always possible to help an applicant, a student, a teacher or a guest to orientate in an educational institution, familiarize with the lecture rooms' plan, show architectural elements to an ordinary viewer and interactively communicate with many elements of the premises' interior;

3. The project can be used in advertising and career-oriented work.
Thus, the problem of training of future engineers-teachers of the computer profile by means of the use of 3D editors is of interest and requires further development of objectives, content, methods of its formation, skills, thinking with taking into consideration the peculiarities of educational, educational and qualification levels, profession, and the priority areas of development of modern possibilities of tools of computer technologies.

\section{REFERENCES}

[1] Kravchuk T. (1998). Educational problems in vocational training of university students using the computer. Barnaul, Sciences, 165.

[2] Hern D. (2005). Computer graphics and standard OpenGL. Moscow: Baker M.P.

[3] Bondarenko M. YU., Bondarenko S. V. (2008) 3ds Mah 2008 za 26 urokov (+CD), 1-e izdanie, Izdatell'skiidom III"DialektikallI", 2008. - 304 s.

[4] Ivanov V. \&Batrakov A. (1995). Threedimensional computer graphics. M.: Radio and communication, Ed. G.M. Polishchuk, 224.

[5] Murdock K. (2007). Autodesk 3ds Max 9. User's Bible. EEUU: Dialectics.

[6] Plaksin A. A., Lobanov A. V. (2012) Mental ray/iray. Masterstvovizualizacii v Autodesk 3ds Max - M.: DMK Press, 2012. -258 s.: il.

[7] Chehlov D.A. (2015) Vizualizacija v AUTODESK MAYA. Mental ray renderer. - M.: DMK Press, 2015. - 696 s.

[8] BocharI.Yu. Metodichniaspektipidgotovkifahivtsivinzh enerno-pedagogichnogonapryamku do vikoristannya ADOBE PHOTOSHOP CS5 u redaktsiyno-vidavnichihsistemah / I.Yu. Bochar // Kompyuternointegrovanitehnologiyi: osvita, nauka, virobnitstvo :naukoviyzhurnal. - Lutsk. Vidavnitstvo LNTU, 2011. - S. 23-30

[9] Rice S. (2009). Character Animation in 3D Studio MAX. EEUU: Publish. BOOKS.

[10] Yu K. (2008). 3ds Max in Design of Environment. St. Petersburg: BHVPetersburg.

[11] Khomenko V. (2013). Computer graphics packages: a tutorial for students. Donetsk: Landon, XXI, 232.

[12] Kelli L. Myerdok. (2013) Autodesk 3ds Max 2013. Biblijapol'zovatelja (+ CDROM). Izdatel'skiidom \"Dialektikal". Per. s angl. - M.: $2013-816$ s. s il. 
[13] Timofeev S. M. ( 2014) 3ds Max 2014. SPb.: BHV-Peterburg, 2014. - 512 s.: il. + Videokurs - (V podlinnike)

[14] Milovskaja O. (2017) 3ds Max 2017. Dizaininter'eroviarhitektury. - Sanktpeterburg: «Piter», 2017 - 416 s. s il.

[15] Snuk G. (2007) 3D-landshafty v real'nomvremenina C++ i DirectX 9. - 2-e izd. - M.: Kudic-press, 2007. - 368 s.

[16] Stefani Ris. (2009) Animacijapersonazhei $\mathrm{v}$ 3D Studio MAH, original Animacijapersonazhei v 3D Studio MAH. Izdatel'stvo BOOKS, 2009. - 450s.

[17] ShammsMort'e. (2007)Autodesk 3ds Max 9 dlja \"chainikovl". 3d Studio Max 9: Per. s angl. - M.: Izdatel'skiidom \"Dialektika , 2007. - 384 s. s il.

[18] Lee J. (2002). Three-dimensional graphics and animation. EEUU: M. Williams.

[19] Shvemberger S. (2006). 3ds Max: Art Modeling and Special Effects. St. Petersburg: BHV-Petersburg.

[20] Mortier S. (2007). Autodesk 3ds Max 9 for "Dummies". Moscow: Publishing House "Dialectics". 